pulmonary nodules without the need to convert to lobectomy or open thoracotomy.

\section{References}

1. Parsons AM, Detterbeck FC, Parker LA. Accuracy of helical CT in the detection of pulmonary metastases: is intraoperative palpation still necessary? Ann Thorac Surg. 2004;78:1910-8.

2. Eichfeld U, Dietrich A, Ott R, Kloeppel R. Video-assisted thoracoscopic surgery for pulmonary nodules after computed tomography-guided marking with a spiral wire. Ann Thorac Surg. 2005;79:313-7.
3. Cerfolio RJ, McCarty T, Bryant AS. Non-imaged pulmonary nodules discovered during thoracotomy for metastatectomy by lung palpation. Eur J Cardiothorac Surg. 2009;35:786-91

4. Madajewski B, Judy BF, Mouchli A, Kapoor V, Holt D, Wang MD et al. Intraoperative near-infrared imaging of surgical wounds after tumor resections can detect residual disease. Clin Cancer Res. 2012; 18:5741-51

5. Schaafsma BE, Mieog JS, Hutteman M, van der Vorst JR, Kuppen PJ Lowik CW, et al. The clinical use of indocyanine green as a near-infrared fluorescent contrast agent for image-guided oncologic surgery. J Surg Oncol. 2011;104:323-32.

\title{
Successful recovery from respiratory failure by external distraction sternoplasty in a patient with Jeune syndrome
}

\author{
Samina Park, MD, Chang Hyun Kang, MD, PhD, In Kyu Park, MD, PhD, and Young Tae Kim, MD, PhD, \\ Seoul, Republic of Korea
}

Jeune syndrome (JS), known as asphyxiating thoracic dystrophy, is a rare autosomal recessive disorder, reported by de Vries and colleagues ${ }^{1}$ in 1945. Abnormal endochondral bone formation causes a small, narrow, and noncompliant thorax. Pulmonary complications resulting from the restrictive thoracic cage are the primary cause of

\footnotetext{
From the Department of Thoracic and Cardiovascular Surgery, Seoul National University Hospital, Seoul National University College of Medicine, Seoul, Republic of Korea.

Disclosures: Authors have nothing to disclose with regard to commercial support. Received for publication July 22, 2014; revisions received Oct 29, 2014; accepted for publication Nov 6, 2014; available ahead of print Dec 10, 2014.

Address for reprints: Chang Hyun Kang, MD, PhD, Department of Thoracic and Cardiovascular Surgery, Seoul National University Hospital, 101 Daehak-ro, Jongno-gu, Seoul 110-744, Republic of Korea (E-mail: chkang@ snu.ac.kr). J Thorac Cardiovasc Surg 2015;149:e53-5 $0022-5223 / \$ 36.00$

Copyright (C) 2015 by The American Association for Thoracic Surgery http://dx.doi.org/10.1016/j.jtcvs.2014.11.030
}

death, and up to $80 \%$ of the children with JS die as a result of recurrent pulmonary infection. ${ }^{1}$ Herein, we report a case of a patient who successfully recovered from respiratory failure after thoracic cage enlargement, through gradual external distraction of the sternum.

The diagnosis of JS was made at a gestational age of 22 weeks. The patient was born at full term via spontaneous vaginal delivery; however, he was diagnosed with recurrent pulmonary infection and respiratory distress and was repeatedly admitted to the intensive-care unit. At the age of 7 months, he underwent tracheostomy and was dependent on a mechanical ventilator. At the age of 22 months, he was transferred to our institute for surgical correction of restrictive chest. His height and chest circumferences were below the 25th percentile for his age. The chest computed tomography scan revealed a narrow bell-shaped thoracic cage, which induced extrinsic compression of the left main bronchus, atelectasis, and hypoinflation of both lungs. The venous blood gas analysis

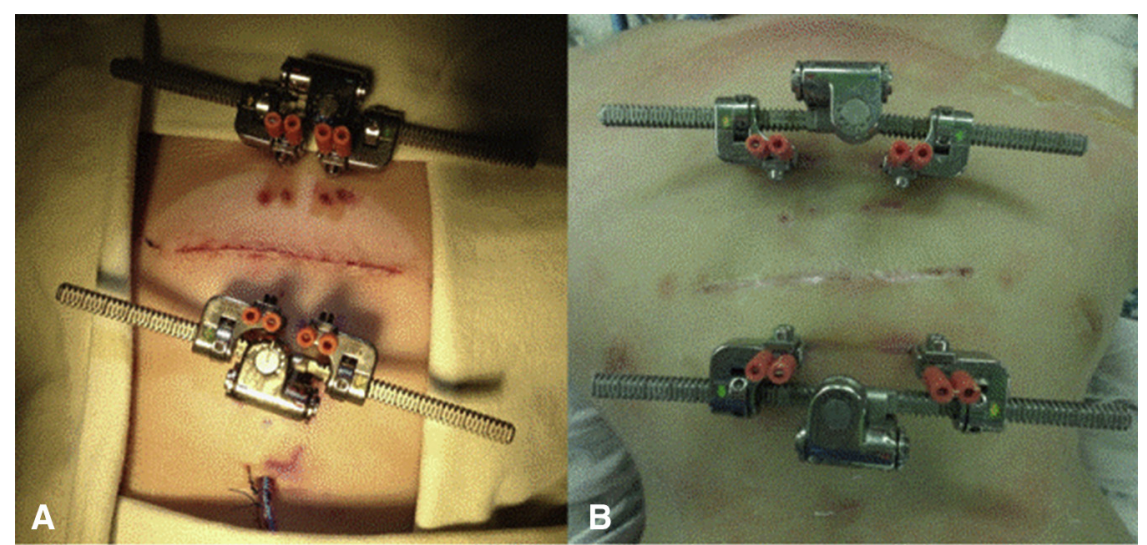

FIGURE 1. The figure shows (A) a photograph taken immediately after surgery; and (B) a photograph taken at postoperative week 3. 


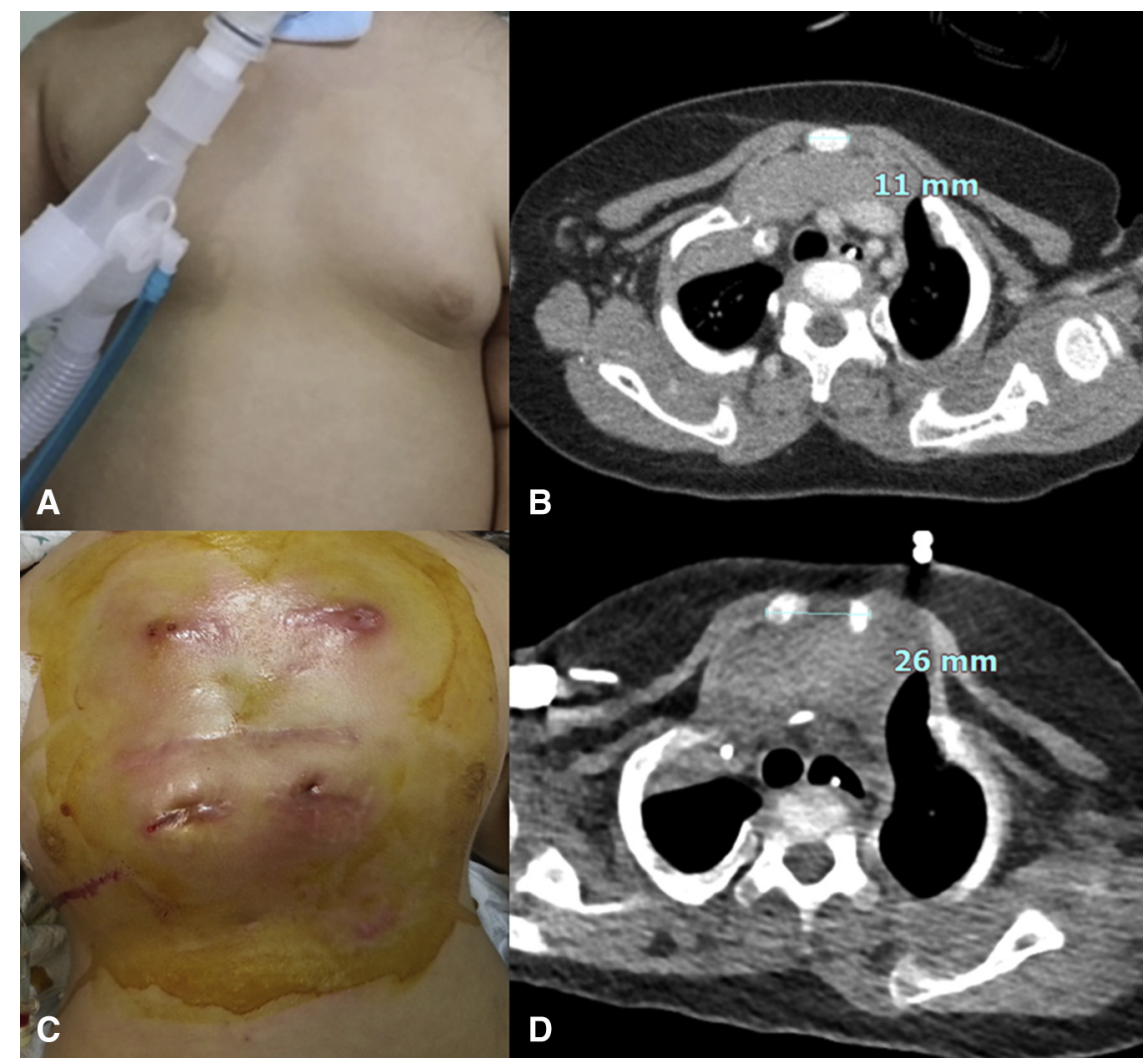

FIGURE 2. The figure shows (A) a photograph taken before surgery; (B) the sternal width before surgery at the 2nd intercostal space was $11 \mathrm{~mm}$ and the anteroposterior diameter at carina was $55 \mathrm{~mm}$ in chest computed tomography scan before surgery; (C) a photograph after device removal; and (D) the sternal width was increased to $26 \mathrm{~mm}$ and the anteroposterior diameter at carina to $66 \mathrm{~mm}$ after removal of devices.

revealed severe hypercapnia, and the partial pressure of $\mathrm{CO}_{2}$ was $75 \mathrm{~mm} \mathrm{Hg}$.

As the patient had poor respiratory function, we thought that the conventional lateral thoracic expansion would be risky for him. Therefore, we decided to apply the distraction osteogenesis technique and expected to achieve gradual remodeling of the thoracic cage. This technique has been used to reconstruct skeletal deformities and lengthen the long bones of the body, inducing regeneration and remodeling of the bone, cartilage, and adjacent soft tissues. ${ }^{2}$ After the gradual and controlled displacement of a bone fragment, obtained by osteotomy, the callus and soft tissues slowly generated between the osteotomized bones.

With use of this procedure, we expected that bone volume and thoracic cavity size would increase together over time, with improvement in respiratory function. We used an external distraction device (MultiGuide II, model 62-01010, 35 mm; Stryker Leibinger Inc, Kalamazoo, Mich), which was originally designed for midface distraction osteogenesis in cases of mandibular fracture or craniofacial anomaly. Median sternotomy was performed after a transverse skin incision to reduce tension on the skin during the distraction phase. Great care was taken to minimize the damage to the periosteum by electrocautery. Small holes were drilled in the body of the sternum for insertion of the fixation pins. Four pins were inserted through the skin to fix each device in place, and the sternum was reapproximated by tight locking of the devices (Figure 1, A). Sternal stability was checked manually, so as not to disturb respiratory function.

The patient had a latency phase of 1 week, and a distraction phase of 7 weeks, with lengthening at a rate of $1 \mathrm{~mm}$ per day (Figure 1, B). ${ }^{3}$ During the distraction period, 1 of the pins in the lower device was dislocated because of fracture of the sternum. Reinforcement of the pin insertion site, with a titanium plate, and repositioning of the device were needed. Otherwise, no procedure-related complications occurred until removal of the devices.

After a consolidation phase of 4 weeks, the devices were removed safely, under local anesthesia. Over 11 months of follow-up, the patient was able to be weaned from the home ventilator, with only intermittent ventilatory support during the night. The serial chest computed tomography scans revealed that the anteroposterior diameter of the thoracic cage and the sternal width increased (Figure 2, A-D). In addition, estimated total lung volume increased by $21 \%$ (178 $\mathrm{mL}$ to $217 \mathrm{~mL}$ ). The partial pressure of $\mathrm{CO}_{2}$ gas in 
the blood decreased to $60 \mathrm{~mm} \mathrm{Hg}$ without ventilatory support.

\section{DISCUSSION}

Distraction osteogenesis is a new surgical technique for the treatment of JS. The most important advantage of this technique compared with lateral thoracic expansion is the preservation of respiratory function by avoiding extensive rib division. ${ }^{4}$ Therefore, this technique can be applied safely in a patient with respiratory failure. Moreover, gradual enlargement and remodeling of the thoracic cage can be expected. Although a case of distraction osteogenesis using an internal distraction device in a neonate with JS has been reported, ${ }^{5}$ this case is the first using an external distraction device. An external device is more convenient for adjusting the distraction length, and it can be easily removed under local anesthesia. In conclusion, we report a case of successful recovery from respiratory failure, by external distraction sternoplasty in a patient with JS.

\section{References}

1. de Vries J, Yntema JL, van Die CE, Crama N, Cornelissen EA, Hamel BC. Jeune syndrome: description of 13 cases and a proposal for follow-up protocol. Eur J Pediatr. 2010;169:77-88.

2. Ilizarov GA. The tension-stress effect on the genesis and growth of tissues. Part I The influence of stability of fixation and soft-tissue preservation. Clin Orthop Relat Res. 1989;238:249-81.

3. Ilizarov GA. The tension-stress effect on the genesis and growth of tissues: Part II The influence of the rate and frequency of distraction. Clin Orthop Relat Res. 1989;239:263-85.

4. Davis JT, Heistein JB, Castile RG, Adler B, Mutabagani KH, Villalobos RE, et al Lateral thoracic expansion for Jeune's syndrome: midterm results. Ann Thorac Surg. 2001;72:872-8.

5. Conroy E, Eustace N, McCormack D. Sternoplasty and rib distraction in neonatal Jeune syndrome. J Pediatr Orthop. 2010;30:527-30. 